\title{
Word feature encoding: Synonym and antonym discrimination after generating synonyms or antonyms*
}

\author{
HERMAN BUSCHKE \\ The Saul R. Korey Department of Neurology \\ and Rose F. Kennedy Center \\ for Research in Mental Retardation and Human Development \\ Albert Einstein College of Medicine, Bronx, N.Y. 10461 \\ and \\ JUDAH RONCH \\ Vassar College, Poughkeepsie, N.Y. 12601
}

Correct recognition of originally presented words or their synonyms, and false recognition of their antonyms, was tested by forced choice among original word, antonym and two distractors, or among synonym, antonym, and two distractors, after study of original words alone, after synonym generation, and after antonym generation. Synonym recognition was as good as recognition of original words only when synonyms were generated during presentation. Generating antonyms decreased recognition of original words but not of synonyms, which always were chosen more often than antonyms. Words appear to be represented and related by component features rather than as unitary elements or concepts.

The problem of how words are represented in memory is a relevant and important case of the more general problem of "the possible formal structure of a memory trace," treated by Bower (1967). Are words encoded and represented as indivisible unitary elements, as multicomponent complexes of attributes or features, or as concepts or meanings that they exemplify? Studies of verbal recognition and discrimination by Anisfeld \& Knapp (1968), by Fillenbaum (1969), and by others concerned with this problem have provided evidence for the view that words may be represented as complexes of features (Buschke \& Lenon, 1969; Grossman \& Eagle, 1970). This report presents new findings that demonstrate that words may be represented and remembered as multicomponent units, rather than as indivisible unitary elements, or as concepts exemplified by words. These results were obtained by a new and potentially useful method that involves determining how well a synonym may substitute for an originally presented word and be discriminated from its antonym in recognition.

\section{METHOD}

In the three experiments reported here, 36 simple common words 1 were read aloud to the $\mathrm{Ss}$, who were

*This research was supported by USPHS Grants MH-17733 to Herman Buschke from NIMH, NB-03356 from NINDS, and HD-01799-07 from NICHD. We thank Moshe Anisfeld, Walter Kintsch, and James Greeno for critical discussion. Reprint requests should be sent to $H$. Buschke. The Saul R. Korey Department of Neurology, Albert Einstein College of Medicine, 1300 Morris Park Ave., Bronx, N.Y. 10461. instructed to remember and think about the meaning of each word for $5 \mathrm{sec}$ so that they could choose each word from a group of four words in the subsequent test. The experiments were identical except for the processing instructions given before presentation of the words to be remembered. The different instructions given before presentation were: (I) remember each word and think about its meaning; (II) remember each word, think about its meaning, and generate a synonym; (III) remember each word, think about its meaning, and generate an antonym. In the recognition test, there were 36 test trials, each consisting of a group of four words. In 18 test trials, the four words included an originally presented word, its antonym, and two new distractors which were antonyms of each other. In the other 18 test trials, however, a synonym replaced an originally presented word.

Half of the presented words were tested for recognition of the original word itself and half for synonym recognition because, while it is easy to generate antonyms, synonym generation is difficult for some original words. Because fair evaluation of the relationship of synonyms and antonyms to originally presented words requires that synonyms as well as antonyms be accessible, synonym recognition was tested for those original words having reasonably accessible synonyms. Those test trials containing originally presented words and those containing synonyms (instead of original words) occurred in random order. There were two versions of the recognition test, each of which was given to approximately half of the Ss in all three experiments. In one version, related items were adjacent to each other, while in the other they were not. For example, for the originally presented word "inside,' the test trial in one version read: inside, outside, alone, together; the test trial in the other version read: inside, alone, outside, together. An illustration of how a synonym replaced an originally presented word was the test trial for the original word "happy," where the test trial contained the words sad, cheerful, solid, hollow. The results of both versions are reported together. Because of a typographical error in Test Trial 30 (for an original word) in one version, that trial was not included in the present analysis.

In Experiment I, Ss were informed before the test, but after presentation of the original words, that synonyms would replace originally presented words in half of the test trials. In all experiments, Ss were told to circle the originally presented word in each test trial if present and otherwise to circle the word that was closest to an originally presented word. They were allowed $15 \mathrm{sec}$ for each test trial. Experiment II was identical except that Ss were instructed to generate a synonym for each word as it was presented, because in the test trials they would be required to choose either originally presented words or their synonyms. In Experiment III, Ss were instructed to generate an antonym for each word presented, because in the test trials they would be asked to choose the original word from a group of four words that would include an antonym of the originally presented word. These Ss were not informed before presentation that they would be required to choose synonyms as well as originally presented words in the test trials.

The Ss were undergraduate college students, who were tested in separate experimental groups. The number of $\mathrm{Ss}$ in each experiment is given as $\mathrm{N}$ in Table 1.

\section{RESULTS}

The results are presented in Table 1 , which shows the mean proportion of test trials in which an original word or a synonym was chosen. Table 1 also shows the relative choice of antonyms and distractors in those trials containing an original word and in those containing a synonym. Because two distractors appeared in each test trial, the mean choice of distractors was divided by two, for comparison of the relative choice of distractors with original words, synonyms or antonyms, each of which occurred only once in any test trial. In order to normalize the distribution of data, the relative choices were converted into 
Table 1

Mean Proportion of Choices of Original Words, Synonyms, Antonyms, and Distractors

\begin{tabular}{|c|c|c|c|c|c|c|}
\hline \multirow[b]{2}{*}{$\begin{array}{l}\text { Processing } \\
\text { Instruction }\end{array}$} & \multirow[b]{2}{*}{ Original } & \multirow[b]{2}{*}{ Synonym } & \multicolumn{2}{|c|}{ Original Present } & \multicolumn{2}{|c|}{ Synonym Present } \\
\hline & & & Antonym & $\begin{array}{c}\text { Distrac- } \\
\text { tor* }\end{array}$ & Antonym & $\begin{array}{c}\text { Distrac- } \\
\text { tor } *\end{array}$ \\
\hline $\begin{array}{l}\text { I Original } \\
(N=18)\end{array}$ & $\begin{array}{r}.77 \\
2.18 \\
.08\end{array}$ & $\begin{array}{r}.46 \\
1.49 \\
.10\end{array}$ & $\begin{array}{ll}.09 & \\
& .50 \\
& .08\end{array}$ & $\begin{array}{rr}.07 & \\
& .48 \\
& .05\end{array}$ & $\begin{array}{r}.25 \\
1.03 \\
.06\end{array}$ & $\begin{array}{r}.14 \\
.76 \\
.05\end{array}$ \\
\hline $\begin{array}{l}\text { II Synonym } \\
(N=22)\end{array}$ & $\begin{array}{r}.76 \\
2.16 \\
.09\end{array}$ & $\begin{array}{r}.68 \\
2.00 \\
.10\end{array}$ & $\begin{array}{rr}.12 & \\
& .64 \\
& .07\end{array}$ & $\begin{array}{rr}.06 & \\
& .43 \\
.06\end{array}$ & $\begin{array}{r}.16 \\
.72 \\
.09\end{array}$ & $\begin{array}{ll}.08 & \\
-51 \\
.05\end{array}$ \\
\hline $\begin{array}{l}\text { III Antonym } \\
(N=16)\end{array}$ & $\begin{array}{r}.63 \\
1.84 \\
.06\end{array}$ & $\begin{array}{r}.47 \\
1.50 \\
.09\end{array}$ & $\begin{array}{r}.24 .00 \\
.08\end{array}$ & $\begin{array}{rr}.06 & \\
& .48 \\
& .05\end{array}$ & $\begin{array}{r}.31 \\
1.16 \\
.08\end{array}$ & $\begin{array}{rr}.11 & \\
& .66 \\
& .05\end{array}$ \\
\hline
\end{tabular}

Note-Numbers in italics represent arc-sine transformed scores and standard errors * Distractor choice divided by 2 for comparison

proportions (of the number of test trials), and then converted into arcsine transformed scores (Walker \& Lev, 1953). Comparisons were made using two-tailed t tests on the arcsine transformed scores; all differences indicated here were significant at least at the $5 \%$ level.

The most critical findings are those in the columns headed "Original" and "Synonym." In I, recognition of original words was substantially greater than recognition of synonyms $(\mathrm{t}=4.95, \mathrm{df}=17, \mathrm{p}<.001)$. In II, when Ss were instructed to generate synonyms of originally presented words, recognition of synonyms was as good as recognition of original words $(t=1.95$, df $=21, p>.05)$, but recognition of original words was not increased (or decreased; $\mathrm{t}=.16, \mathrm{df}=$ $38, p>.10$ ). Although $S s$ were not required to write down the synonyms and antonyms they generated, the results of II and III clearly indicate that $S s$ did generate synonyms and antonyms, respectively, in those experiments. The recognition of synonyms in I and II clearly demonstrated that these words were not remembered as the specific common concepts that they exemplified, since recognition of synonyms was as good as recognition of original words only in II, when Ss generated and encoded synonyms. The sense of "concept" intended here is that by virtue of which two words are regarded as synonyms or antonyms. Thus, "loud" and "noisy" may be said to exemplify a specific common concept, while "loud" and "quiet" both represent a more general underlying concept.

Experiment III shows that generating an antonym of original words decreased recognition of original words (III $<\mathrm{I}: \mathrm{t}=3.21, \mathrm{df}=$ $32, \mathrm{p}<.01$ ) with an increase in choice of antonyms (III $>$ I: $t=4.06, \mathrm{df}=$ $32, p<.001$ ), but without an increase in the overall choice of both original words and antonyms together; i.e., the relative choice of distractors was not decreased (DIII $=\mathrm{DI}: \mathrm{t}=.006$, $\mathrm{df}=$ $32, p>.10)$. These results indicate that these words were not remembered as the more general underlying concepts they exemplify, since original words and their antonyms both represent the same more general concept. Furthermore, generation of antonyms in III did not decrease the relative choice of synonyms (III $=\mathrm{I}: \mathrm{t}$ $=0.084, \mathrm{df}=32, \mathrm{p}>.10$ ), which were still chosen more often than were antonyms $(\mathrm{t}=2.24, \mathrm{df}=15, \mathrm{p}<.02)$.

In all three experiments, original words were chosen substantially more often than synonyms (except in II; $t$ (I) $=4.95, \mathrm{df}=17, \mathrm{p}<.001 ; \mathrm{t}(\mathrm{II})=1.95$, $\mathrm{df}=21, \mathrm{p}>.05 ; \mathrm{t}(\mathrm{III})=3.64, \mathrm{df}=15$, $p<.01$ ), synonyms were chosen more often than antonyms $[t(I)=3.26$, df $=$ $17, \mathrm{p}<.01 ; \mathrm{t}(\mathrm{II})=6.82, \mathrm{~d} \mathbf{f}=21$, $\mathrm{p}<.001 ; \mathrm{t}(\mathrm{III})=2.24, \mathrm{df}=15$, $p<.02]$, and antonyms were chosen more often than distractors in original and synonym test trials, respectively (except for Io: $\mathrm{t}(\mathrm{Io})=.20$, df $=17$, $\mathrm{p}>.10$, and $\mathrm{t}(\mathrm{Is})=3.82$, df $=17$, $\mathrm{p}<.01 ; \mathrm{t}(\mathrm{IIo})=2.63, \mathrm{df}=21$, $\mathrm{p}<.02$, and $\mathrm{t}$ (IIs) $=2.40, \mathrm{df}=21$, $p<.05 ; \mathrm{t}$ (IIIo) $=3.30, \mathrm{df}=15$ $\mathrm{p}<.01$, and $\mathrm{t}$ (IIIs) $=5.04$, df $=15$, $\mathrm{p}<.001$ ).

These findings indicate that information about at least some components of features of synonyms and antonyms were encoded when they were generated. It is significant that synonyms and antonyms can be generated, since generation of another word having a particular relation to a presented word in itself suggests that words consist of features, which may be used to find words such as synonyms and antonyms. To account for the differential generation of synonyms and antonyms solely in terms of associations between words that do not have component features would seem to require specifically distinguishable associative bonds, as is assumed in current models of long-term memory (Frijda, 1972).

While the data for synonym recognition in Experiments I and II alone, which show that these words were not encoded and retained as specific concepts, might suggest that synonyms were encoded simply as unitary words, generating a synonym could also involve processing and encoding (more) of its component features for recognition. The results of antonym generation in III seem incompatible with the view that these words were encoded simply as unitary elements. If these words were encoded simply as unitary words, recognition of synonyms should have decreased more than recognition of original words when antonyms were generated, since both original words and antonyms would have been encoded, while synonyms would not have been encoded. However, even though antonyms apparently were generated, so that choice of antonyms increased and recognition of original words was decreased, synonym recognition did not decrease but remained substantially greater than antonym choice. The finding in III that synonym recognition was not affected by antonym generation, although recognition of original words was decreased, instead appears to indicate specific interactions in encoding specific words (i.e., interaction between the original words and their antonyms) in terms of their component features, The relative choice of antonyms and original words in III (in contrast to I) suggests that features with opposite values, shared by words such as antonyms, may not be encoded because opposing values may cancel out. Although fewer features of both original words and their antonyms would be encoded than if either had been presented alone, enough features of original words would be encoded to allow the same relative choice of synonyms, because synonyms appear to have more features in common with original words than do antonyms (as shown by the greater choice of synonyms, even in I). The results of II suggest that features with the same value, shared by words such as synonyms, are represented just once for each word, and are not additive.

Finally, the general findings that synonyms were chosen significantly more often than antonyms but less often than original words (except in II when Ss generated synonyms), while antonyms were chosen significantly more often than distractors, shows a differential choice that confirms that words can be encoded as multicomponent units or complexes of features. The relationships between original words, synonyms, antonyms, 
and control distractors demonstrated in these experiments by direct forced choice do not seem surprising but are different from those found in previous investigations using "old-new" false recognition. Fillenbaum (1969) found no significant differences in false recognition of synonyms and antonyms in continuous recognition, while Grossman \& Eagle (1970) found significant false recognition of synonyms but not of antonyms. The method of substitute recognition used here should be useful in further study of the formal structure of verbal memory traces.

While it is clear that words are not necessarily remembered verbatim as particular words but often are remembered only in the sense that meanings or concepts that they convey in context are remembered, the finding that words can be encoded as multicomponent units (which can interact specifically in terms of their shared features) presumably indicates that words are represented in the lexicon of permanent memory as multicomponent units.

\section{REFERENCES}

ANISFELD, M., \& KNAPP, E. Association, synonymity, and directionality in false recognition. Journal of Experimental Psychology, 1968, 77, 171-179.

BOWER, G. H. A multicomponent theory of the memory trace. In K. W. Spence and A. T. Spence (Eds.), Advances in the psychology of learning and motivation. Vol I. New York: Academic Press, 1967. Pp. 229-325.

BUSCHKE, H., \& LENON, R. Encoding homophones and synonyms for verbal discrimination. Psychonomic Science, $1969,14,269-270$

FILLENBAUM, j. Words as feature complexes: False recognition of antonyms and synonyms. Journal of Experimental Psychology, 1969, 82, 400-402.
FRIJDA, N. H. Simulation of human long-term memory. Psychological Bulletin, 1972, 77, 1-31

GROSSMAN, L., \& EAGLE, M Synonymity, antonymity, and association in false recognition responses. Journal of Experimental Psychology, 1970, 83, 244-248.

WALKER, H. M., \& LEV, J. Statistical inference. New York: Holt, 1953. NOTE

1. The original words, followed by their synonyms and antonyms used in the recognition test, were: inside (outside), top (bottom), happy (cheerful, sad), loud (noisy, quiet), sick (ill, healthy), dim (bright), old (new), start (begin, finish), on (off), fat (thin), shout (yell, whisper), naughty (bad, good), quick (fast, slow), front (back), correct (right, wrong), spend (save), dirty (filthy, clean), wet (damp, dry), sweet (sour), under (over), shove (push. pull), smooth (rough), fix (repair, break). empty (full), powerful (strong, weak), easy (hard), scared (afraid, brave), long (short), heavy (light), friend (enemy), talk (speak. listen), rich (wealthy, poor), big (little), dumb (stupid, smart), pretty (beautiful, ugly), win (lose). 